\title{
Optimization of equity allocations of institutional investors: study of Moroccan case
}

\author{
Mustapha Bouchekourte ${ }^{1}$ (D) and Norelislam El Hami ${ }^{2,}{ }^{*}$ (D) \\ ${ }^{1}$ Research Laboratory in Management Sciences Organizations, ENCG, Ibn Tofail University, Kenitra, Morocco \\ ${ }^{2}$ LSI Lab - ENSA, Ibn Tofail University, Kenitra, Morocco
}

Received: 5 May 2021 / Accepted: 29 November 2021

\begin{abstract}
Institutional investors normally define the market segments that present more opportunities for profitability based on their commitments, their financial and accounting situations and the regulations that govern the structure of their investments in equities, bonds, real estate and infrastructure. Their investment strategies consist of defining the allocation of their assets after having fixed the proportion to be invested in each segment. We will try through this work to estimate and optimize the parts of assets invested in shares of pension funds, insurance companies and UCITS (Undertakings for Collective Investments in Transferable Securities), according to their degree of integration into the Moroccan economy, weight of their assets in market capitalization and by the heterogeneity that characterizes their investment decisions on the capital market. Panel data are well suited to our analysis in the sense that they allow us to measure the impact of several actions (stimuli), alone or simultaneously, and the synergies (interactions) of data, which are numerous on investors and on market indicators on the financial market. The results obtained illustrate that the weight of equity investments in portfolios under management of institutional investors are impacted by the share of investors' equity portfolio in market capitalization and by the total assets of this category of investors compared to Morocco's GDP (Gross domestic product).
\end{abstract}

Keywords: Institutional investors / capital market / allocation / casablanca stock exchange / liquidity / volatility / random effects model

\section{Introduction}

The investment strategies of institutional investors differ considerably from a country to another. Asset allocation is influenced by a variety of factors, such as market trends, investment ethics, regulation, risk aversion, cultural factors, governance structures, tax incentives and ultimately the diversity of assets available and eligible for investment [1]. Therefore, there is no justification for keeping asset allocation weights static in dynamic capital markets.

Insurance companies and pension funds have been central to the development of capital markets in developed markets. In the United Kingdom and the United States, where institutional investors are much more present than in most European countries, historically had less restrictive regulations. They helped set up liquid and sophisticated stock markets [2]. Their deep and stable reserves of capital have reduced market volatility.

\footnotetext{
* e-mail: norelislam@outlook.com
}

The behavior of the asset manager tends to be subject to regulatory investment constraints: (a) investment limits in equities, (b) investment limits in international assets, (c) diversification rules, (d) limits on the use of leverage, and (e) limits on the use of derivatives.

Analyzes relating to the liability of actors operating in financial markets show that the behavior of institutional investors appears to be problematic. The accounting and regulatory constraints to which they are subjected to, affect their ability to have convenient long-term vision which leads some of them to liquidate parts of their assets.

\section{Literature review}

\subsection{Factors impacting the strategic allocation of institutional investors}

The behavior observed among institutional investors suggests that their trades have an upstream impact on prices when selecting their trading strategy (Chan and Lakonishok), and ultimately on the development of the financial market as a whole with regard to the realization of the objectives assigned to this matter at the start [3]. 

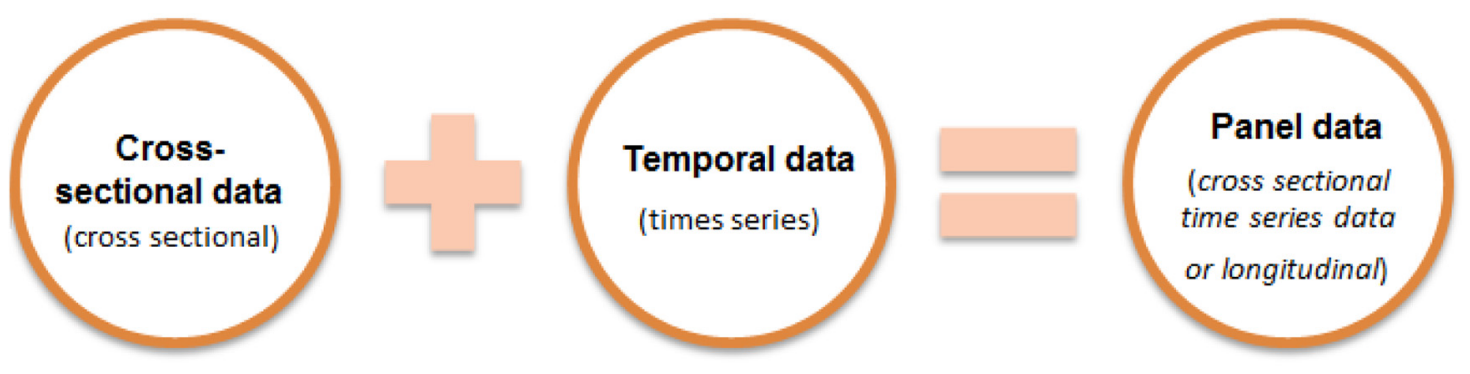

Fig. 1. Panel data: possibility of multilevel analysis (hierarchical).

More recent studies [4] state and confirm that funds that focus on particular sectors can outperform the benchmark. [5] realized that a significant portion of mutual fund managers exhibit stock selection skills that allow them to cover their management costs and generate additional returns. Poor performance of pension fund investments can not only reduce the reserves of current and future retirees, but also increase costs if pension funds fail to honor commitments [6].

When comparing the asset allocation, in sync with movements that characterize the market to explain the variability in performance, we define the asset allocation return component as a deviation in the investment strategy [7].

There is a strong link between the asset allocation policy and the market environment. The market can be relatively stable at times and excessively volatile at others [8]. This means that the risk associated with a traditional (fixed weight) asset investment strategy can be very variable over time.

The possibility of changing an investment strategy according to variations in market volatility leads us to see that an allocation policy sensitive to volatility can lead to a more uniform result and a better compromise between risk and return.

\subsection{Panel data regressions}

Temporal data allow the study of dynamic behavior and changes in correlations over time. It is an instantaneous "image" at a given moment that allows us to study the heterogeneity between individuals [9].

\subsubsection{Specificities of panel data modeling}

The large number allowed by panel data has a very positive consequence on the precision of the estimates since the asymptotic properties, the bias and the variance of the estimate tend towards 0 .

The modeling of these data aims to explain the observable individual and temporal heterogeneity and makes it possible to take into account the influence of omitted variables, sources of unobservable heterogeneity, namely the omission of individual characteristics or the omission of explanatory variables common to all individuals but varying over time [10].
Two types of models are used for panel data. For both types, the challenge is to integrate unobserved heterogeneity.

- Stochastic models

- Econometric models.

For econometric models, the probabilistic nature of the behavior studied is taken into account: a distribution law is applied to the phenomenon studied. Unobserved heterogeneity is taken into account by adding a distribution law on one of the parameters (Mixture).

The nature of the data processed in our analysis (evolution of the investments of 15 institutional investors over 11 years), i.e. 165 lines, led us to use these models because they are best suited to the described data structure.

The model that we would like to estimate is written as:

$$
Y_{i t}=b_{0 i t}+\sum_{k=o}^{n} b k i t X_{i t}^{k}+w_{i t}
$$

$i$ : investor; $t$ : time; $Y$ : variable to be explained: the share of the equity pocket in the investor's total assets; $y_{i t}$ : value of $Y$ for investor $i$ at time $t ; X_{k}$ : explanatory variable: $x_{1}$ is the weight of the equity pocket of investor $i$ in the total market capitalization and $x_{2}$ is the weight of the total assets of investor $i$ in GDP; $x_{i t}^{k^{2}}$ : value of $X^{k}$ for investor $i$ at time $t ; b_{0}$ : constant; $b_{k}$ : parameter to be estimated for the variable $X^{k} ; w_{i t}$ or $\varepsilon_{i}$ : error term.

Unobserved heterogeneity is captured by a constant specific to each individual. Two models are very frequently used to integrate unobserved heterogeneity, they are:

- Fixed effects models: The unobserved individual effects are correlated with the other explanatory variables $X^{k}$.

- Compound error models (random effects): unobserved heterogeneity varies randomly between individuals.

\section{Variables and data}

Based on the theory of institutional investor management styles, and after analyzing data on the yield curve, market capitalization, GDP, (Moroccan All Shares Index), float, deposit rates, turnover rate and the liquidity rate of the stock market, we have retained two variables whose fluctuations are correlated with the weight of the equities in the portfolio of each institutional investor [11]. 


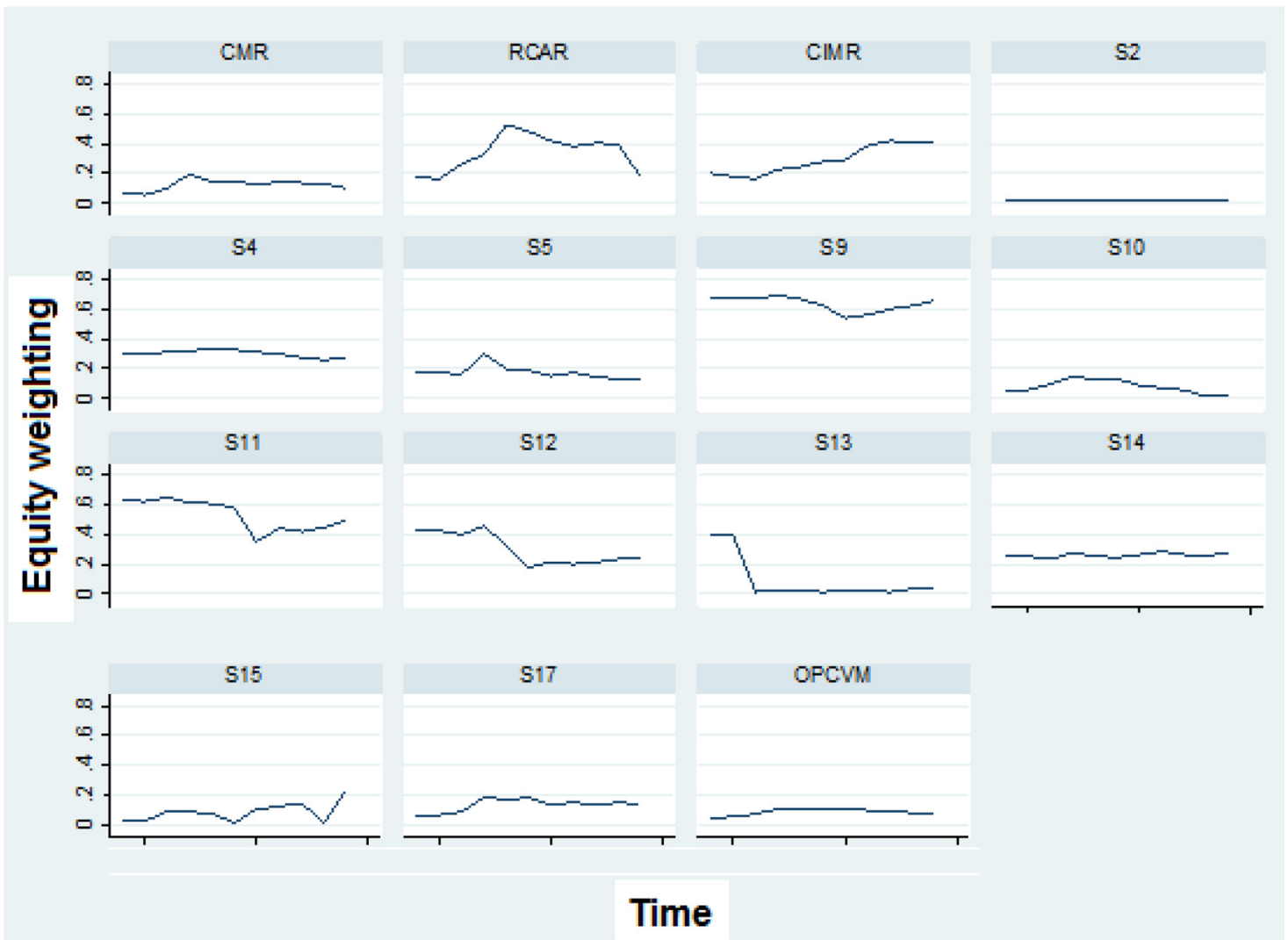

Fig. 2. Evolution of the percentage of equities in the portfolio of the 15 institutional investors before and after the financial crisis.

The data used in this analysis come from national sources (pension funds, insurance companies, UCITS, Ministry of Finance, Bank AL-Maghrib, Financial Market Authority and Casablanca Stock Exchange). The analysis covers several macroeconomic and microstructure variables.

We use detailed data from the operations of different types of investors to study how they affect common factors of liquidity by identifying movements in relation to volume during normal market periods and turbulent times.

The correlation matrix makes it possible to detect the degree of significance of the crossings between these market indicators and the share of equities in the portfolios of the 15 institutional investors that will be the subject of our analysis ( 3 pension funds, 1 aggregate UCITS and 11 companies' insurance which represents more than $90 \%$ of assets under management, in order to avoid spurious regression.

\section{Analysis and estimation results}

The first step is to determine the appropriate model for our data structure: fixed effects or random effects model.

The fe option specifies the fixed effects. The variable id is the identification variable for the cross-sectional dimension of the panel data.
We will estimate the impact of the degree of integration of the activity of a category of institutional investors in the Moroccan economy through:

The report $\frac{\text { Total investor assets }}{\text { GDP }}(\mathbf{X 1})$ and the weight of the equity investment in market capitalization by the ratio $\frac{\text { The weighting invested in equities }}{\text { Market Capitalization }}(\mathbf{X} 2)$ on the portion allocated to equities for each institutional investor (pension fund, insurance company or UCITS) (our explained variable Y2).

\subsection{Estimation of the random effects model}

Unlike the fixed-effects model, the variation between individuals in a random-effects model is assumed to be random and not correlated with the independent variables included in the model.

The crucial distinction between fixed and random effects is whether the unobserved individual effect embodies elements that are correlated with the regressors in the model. If we assume that the differences between individuals have some influence on the dependent variable, then we should use random effects [12]. The advantage of random effects models is that we can include time invariant variables. These variables are absorbed by the intercept in the fixed effects model.

The random effect model is written as follows:

$$
\mathrm{Y}_{\mathrm{it}}=\beta \mathrm{X}_{\mathrm{it}}+\alpha+\mathrm{U}_{\mathrm{it}}+\varepsilon_{\mathrm{it}} .
$$



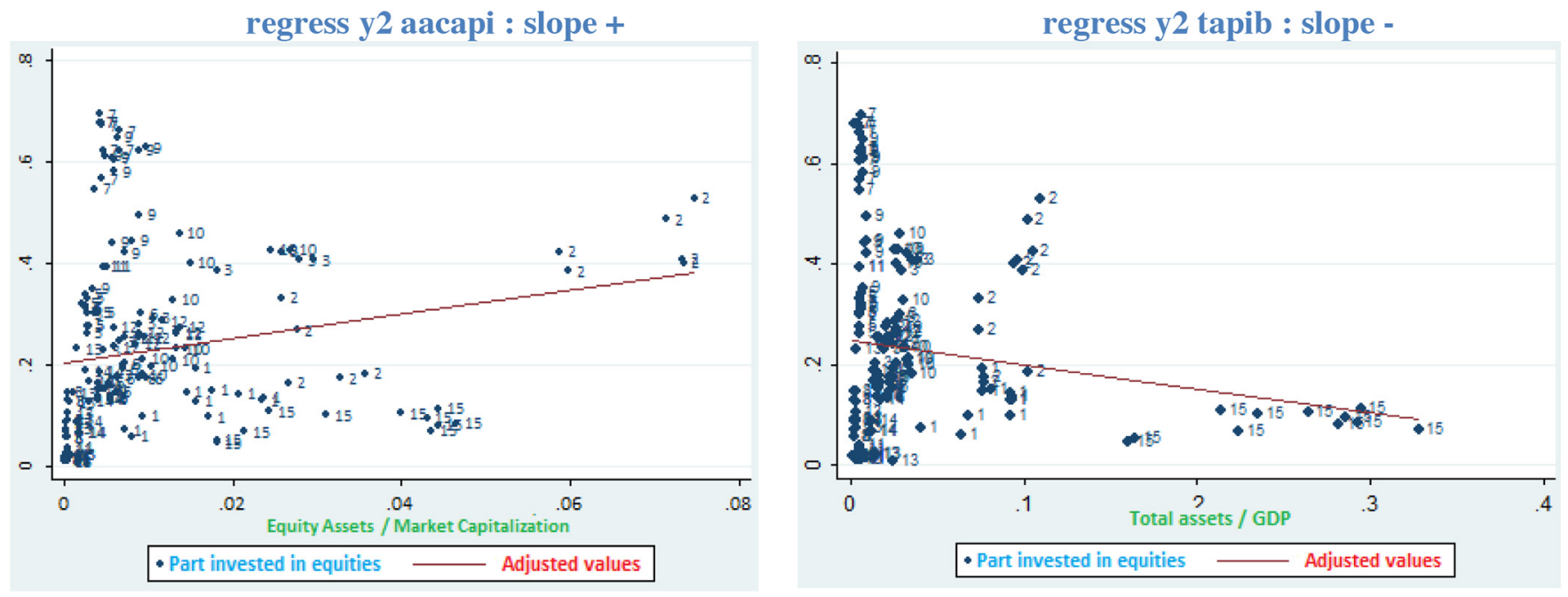

Fig. 3. The effect of the weight of assets on GDP on the allocation of institutional equity investors.

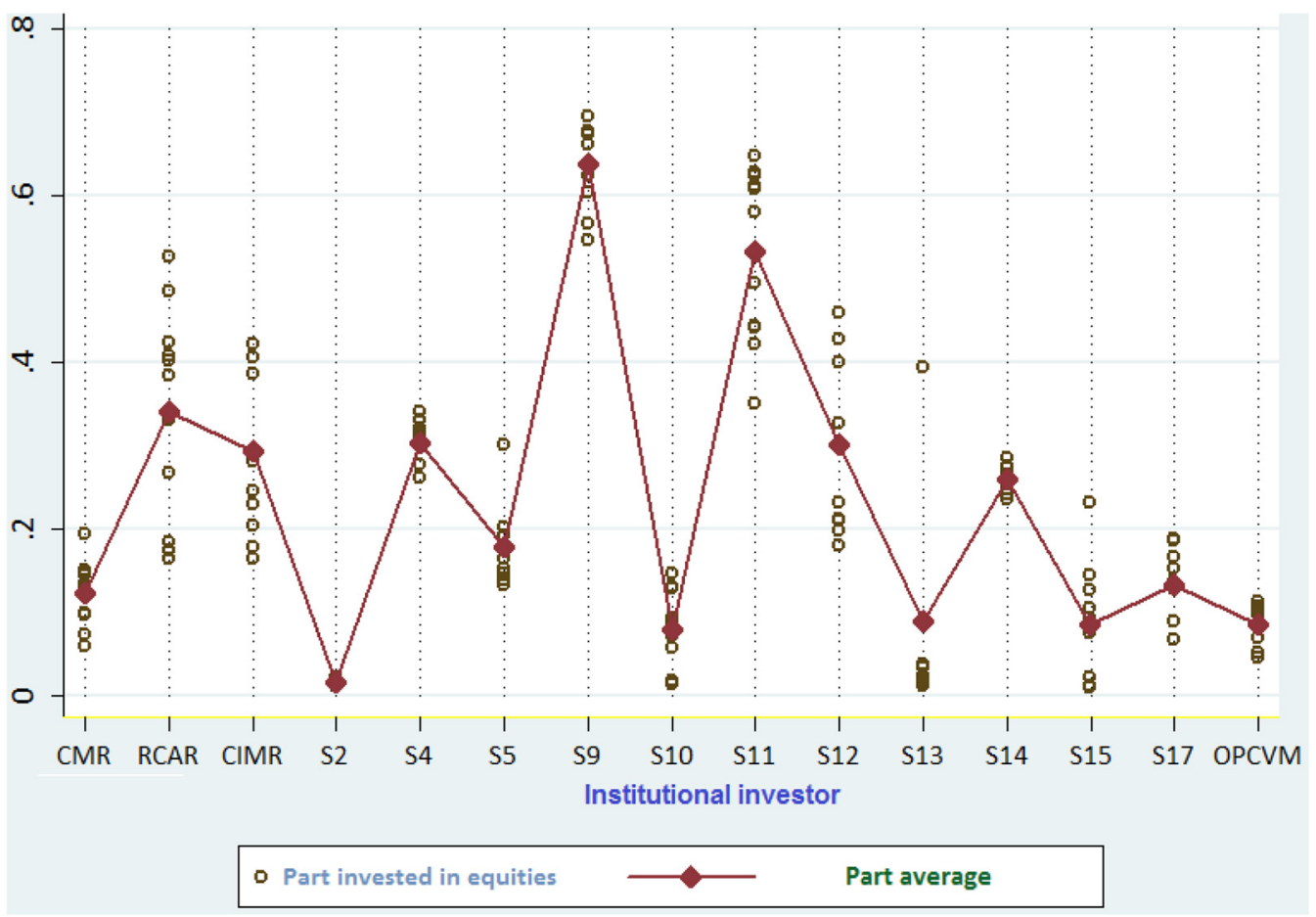

Fig. 4. Annual change in the proportion invested in equities in the portfolios of institutional investors. part.

$U_{i t}$ : betwen part errors; $\square_{i t}$ : the errors of the within

The method works as the following:

The error component model:

$$
\mathrm{Y}_{\mathrm{it}}=\alpha+\mathrm{X}_{\mathrm{it}} \beta+\varepsilon_{\mathrm{it}}
$$

becomes random in the error component model:

$$
\mathrm{Y}_{\mathrm{it}}=\left(\alpha+\mathrm{u}_{\mathrm{i}}\right)+\mathrm{X}_{\mathrm{it}} \beta+\varepsilon_{\mathrm{it}} .
$$

We can generalize this treatment reserved so far for the constant element $\alpha$ to the set of all the coefficients of the model which then becomes:

$$
\mathrm{Y}_{\mathrm{it}}=\left(\alpha+\mathrm{u}_{\mathrm{i}}\right)+\mathrm{X}_{\mathrm{it}}\left(\beta+\mathrm{h}_{\mathrm{i}}\right)+\varepsilon_{\mathrm{it}} .
$$

Random effects assume that the error term does not correlate with the predictors that allow time invariant variables to play a role as explanatory variables. These effects also allow inferences to be generalized beyond the sample used in the model. 


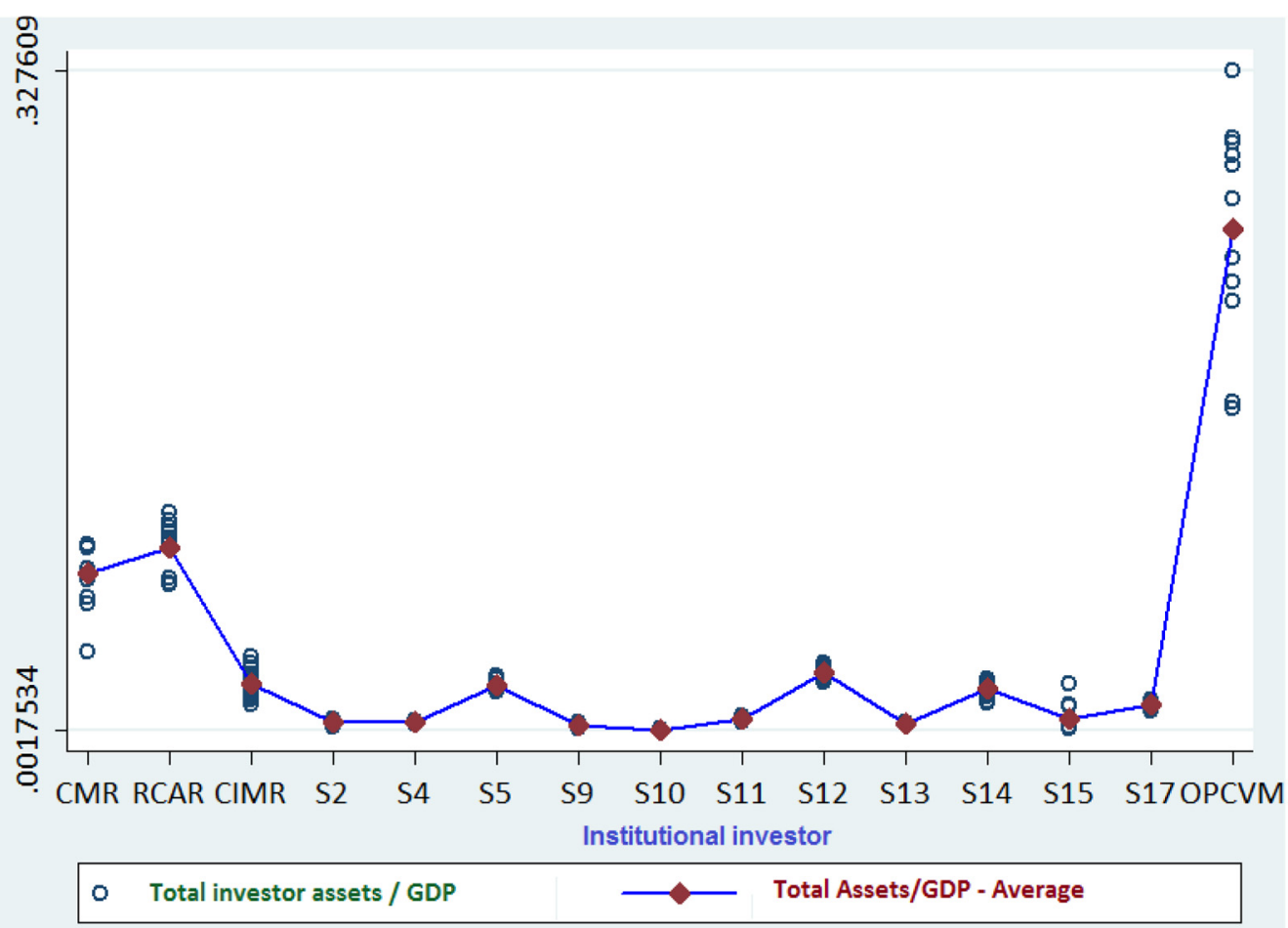

Fig. 5. Annual change in the weight of investor assets in the economy - in points of GDP.

Table 1. Estimation of the random effects model.

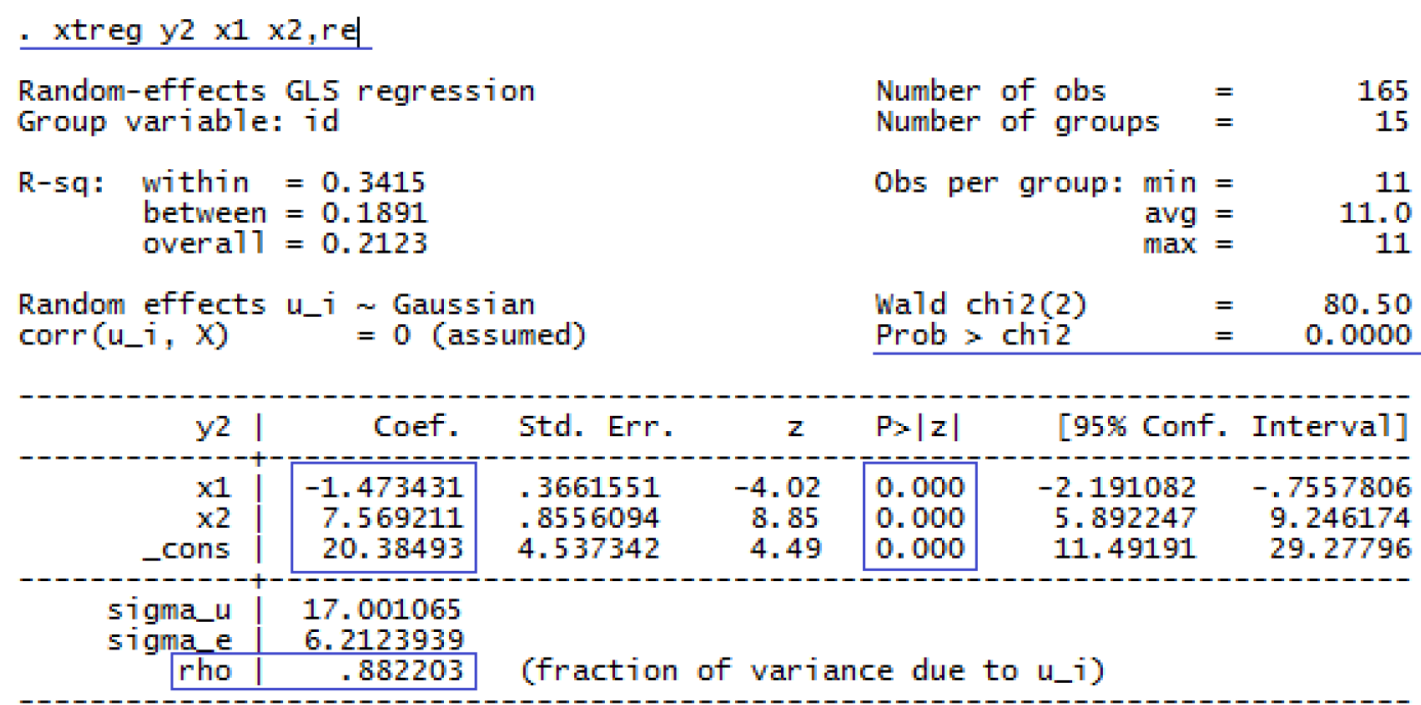




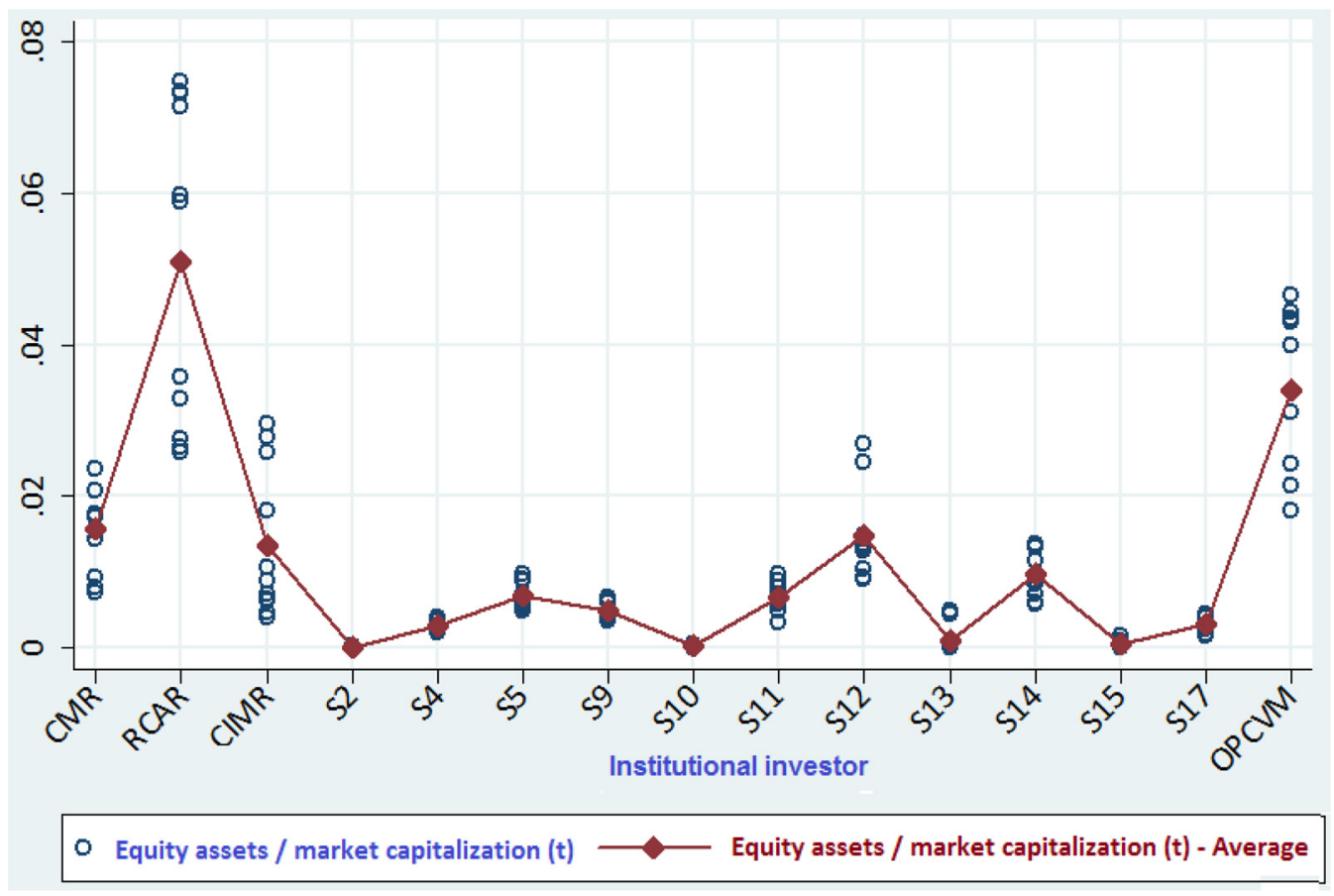

Fig. 6. Annual evolution of the equity pocket of institutional investors in market capitalization.

In this case, the most relevant $R^{2}$ is the $R^{2}$ between, this is the measure of the part of the inter-individual variability of the part of investments in equities explained by those of the variables $\mathrm{X} 1$ and $\mathrm{X} 2$. In the meanwhile, the $R^{2}$ within gives an idea of the contribution of random effects to the model.

$$
R h o=\frac{(\text { sigmau })^{2}}{(\text { sigmau })^{2}+(\text { sigmae })^{2}} .
$$

Rho $=0.882203$ shows that $88.22 \%$ of the variability is due to differences between investors. Rho is an indication of the intra-individual correlation. So there is heterogeneity between the placements of institutional investors.

The effect of the weight of institutional investors' reserves in the Moroccan economy and the preponderance of equity investments in market capitalization on equity allocation decisions (share of the investor's assets allocated to the equity pocket). Each investor has 11 points.

\subsection{The significance of random effects: the Beunsch-Pagan test}

After estimating the random effects model, this test gives the Beunsch-Pagan statistic which tests the significance of the random effects.

The probability of the Beunsch-Pagan test statistic shows that the random effects are globally significant at a threshold of $5 \%$.

\subsection{Hausman's test}

Both fixed-effect and random-effects models take into account the heterogeneity of the data, but the assumptions about the nature of the specific effects differ from model to another. In the first case, we assume that the specific effects can be correlated with the explanatory variables of the model. In the second case we assume that the specific effects are orthogonal to the explanatory variables of the model. Hausman's specification test tests which of these two hypotheses is appropriate for the data. In other words, this test allows us to choose between the fixed effects model and the random effects model.

When the probability of the test is greater than the threshold of $10 \%$ (89.94 in our model), then the Hausman test does not make it possible to differentiate the fixedeffects model from the random-effects model.

The Hausman test is a test of whether the loss in efficiency is worth removing the bias and inconsistency of the OLS (ordinary least squares) estimators. Essentially, Haussman's test tests whether unique errors (Ui) correlate with regressors. The null hypothesis is that the preferred model is the random effects model versus the alternative which corresponds to the fixed effects model).

In this case, the choice of one or the other model must be chosen carefully.

We can nevertheless refer to a few arguments which facilitate the choice of the model:

- When the intra-individual variation of variables is greater than the inter-individual variation, the fixed effects model is more appropriate than the random effects model and vice versa. 


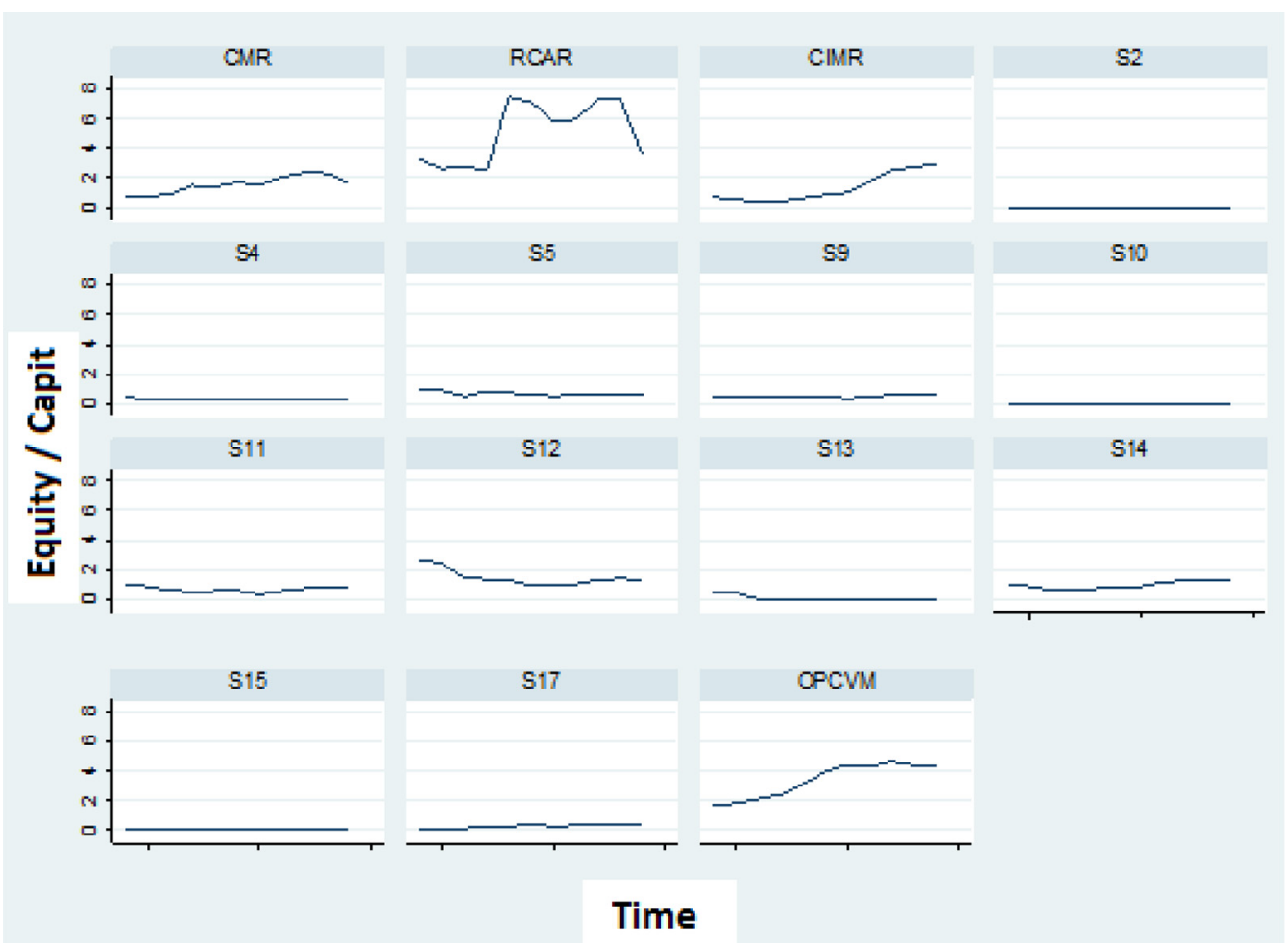

Fig. 7. Weight of institutional investor investments in market capitalization.

- The table in appendices allows grouping the tests on the inter and intra individual variations.

\subsection{Analyzes and regressions}

After having carried out the two types of estimation (with fixed effects and with random effects), and the Hausman test, the model retained is the one with random effects because the inter-individual variation of investors is greater than the intra-individual variation, the random effects model is more appropriate than the fixed effects model [13].

The interindividual variation of the variables is stronger than the intraindividual variation, the random effects model is more appropriate than the fixed effects model:

- The Beunsch-Pagan test showed that the random effects are globally significant at a threshold of $5 \%$.

- The heteroscedasticity test corrected for heteroscedasticity using White's method.

- The residual autocorrelation test allowed us to confirm the hypothesis of no autocorrelation.

- By observing the various parameters of the model selected, namely the coefficients and their statistics, we conclude that the model is very significant.

The weight of equity investments in portfolios under management of institutional investors is impacted:

- Positively by the variable X1 relating to the share of investors' equity portfolio in market capitalization
- Negatively by the total assets of this category of investors compared to GDP.

To illustrate the individual impact of each variable (tapib and aacapi) on the portion allocated to equity investments, we will use the following regressions:

Like the two models previously estimated (fixed and random effects), the estimated coefficient is negative indicating and confirming that the increase in the ratio of total assets to GDP has a negative effect on the allocation of institutional investors in equities.

Likewise, the positive correlation between the portion invested in equities of institutional investors and the weight of their equity pockets in market capitalization is confirmed.

The percentages invested in equities for Moroccan institutional investors are marked by a large dispersion. This share fluctuated between 5 and $20 \%$ before the 2008 crisis and before 2017 for the CMR (Moroccan pension fund), between $17 \%$ and $52 \%$ for RCAR (Collective Retirement Allowance Scheme) and between 15\% and $43 \%$ for the CIMR (Moroccan interprofessional pension fund). This dispersion is explained by the regulations which govern their investment portfolios and by the characteristics of the investment charters which organize the management of their reserves according to their financial and accounting constraints.

The evolution of this part for insurance companies is also very heterogeneous because it did not behave in the same way after the 2008 crisis. This heterogeneous trend is 


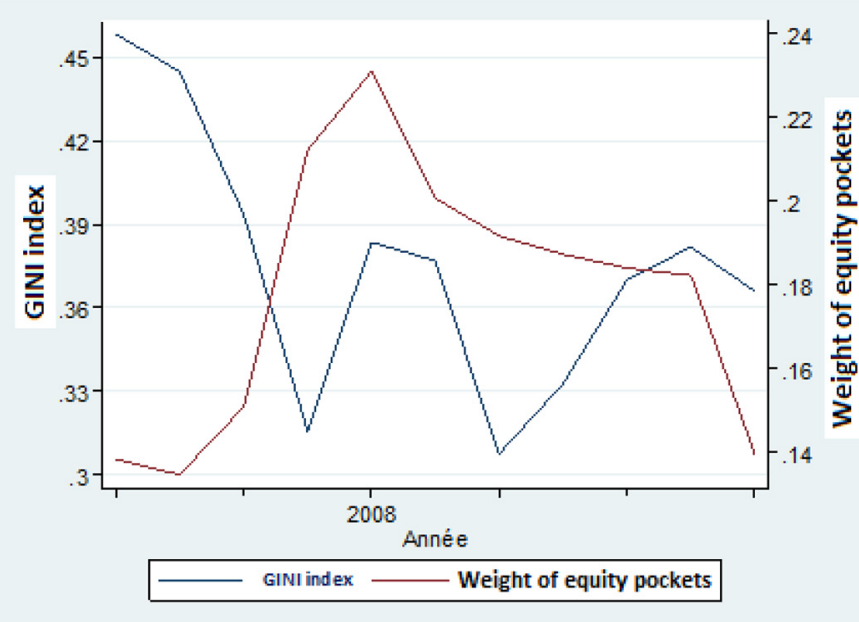

Fig. 8. GINI index and weight of equity pockets in institutional investor assets.

explained by the level of risk borne by these insurance companies, and that depends on the eligibility of their reserve funds.

Individual institutional savings in points of GDP provide information on the weight of each investor in the Moroccan economy. This ratio makes it possible to assess the degree of integration of savings of pension funds and insurance companies and of the net assets of UCITS into the economy [14].

Over our 15-year period of analysis, the weight of insurance companies' investments in GDP has not changed significantly. On the other hand, the Moroccan pension funds, CMR, CIMR and RCAR have become increasingly represented in the Moroccan economy. This finding is more evident for UCITS whose net assets have not stopped growing since their establishment in 1996. Similarly, the UCITS remains the most accessible investment vehicle for all institutional profiles (banks, companies, pension funds, insurance companies and individuals). Thus, the net assets managed by UCITS constituted almost a third of GDP at the end of 2015.

The exploration of the share of equity investments in the portfolios of each institutional investor - through the graph below - shows that the reaction of insurance companies to the downward cycle that the stock market experienced after 2008 did not was not characterized by a withdrawal from the equity market or by a reallocation of their investments in favor of other compartments of the capital market. On the other hand, RCAR and UCITS revised their shares allocated to equities following the financial crisis of 2008 .

The percentages presented in the graph above also show the underweighting of equity assets in the portfolios of institutional investors, whose investment decisions are characterized by increased vigilance. Investments in shares of pension funds, for example, do not even reach the levels allowed by the regulations [15].

This structure calls into question their role as long-term investor in the financial market, and more specifically in its equity compartment. These results call into question the
Table 2. Breusch and Pagan test - random effects.

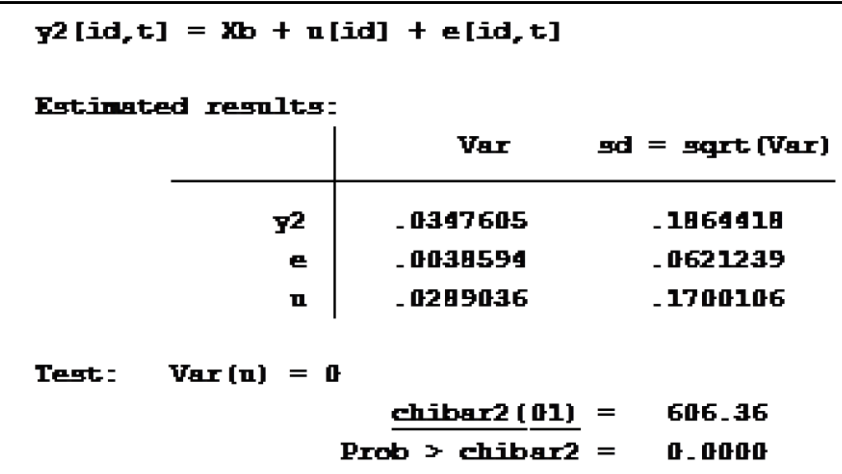

Output by STATA: Software for Statistics and Data Science

possibility for Morocco to adhere to the Anglo-Saxon model favoring a higher degree of liberalism of investments in the financial market. Thus, if the authorized limits for investments in equity pockets are not reached, for pension funds and for insurance companies, the observed underweighting of this type of asset in the portfolios of institutional investors has other determinants in connection with the depth of the market, its profitability and the offer in terms of listed companies. This last factor impacts not only the units reserved for the equity pockets, but also the possibility that institutional investors should have to apply management styles specific to their investment constraints or to apply the principle of diversification which allows them to hedge against investments in any sectoral fluctuations of listed companies.

Starting from the returns of the Moroccan stock market which, despite their decline in recent years, recorded an average exceeding $12 \%$. It can be concluded that institutional investors underweighted their equity pockets in favor of treasury bills and fixed income assets whose profitability did not exceed on average $4.5 \%$.

\section{Interpretations and discussions}

The exploration of data relating to the investments of institutional investors and the structure of the Moroccan stock market makes it possible to define the connecting mechanisms between investment decisions and their degrees of integration into the Moroccan economy. Thus, this analysis makes it possible to identify avenues for improving its structure marked by low liquidity.

The first step is to seek to increase the float. Likewise, it is necessary to introduce companies which have a significant weight in the economy and whose fundamentals can attract investors, especially institutional investors [16].

The major problem with the depth of the Moroccan financial market is the nature of the players in the stock market. The development of recent years has been that institutional investors have gradually withdrawn from the equity markets. 
Table 3. Hausman's test.

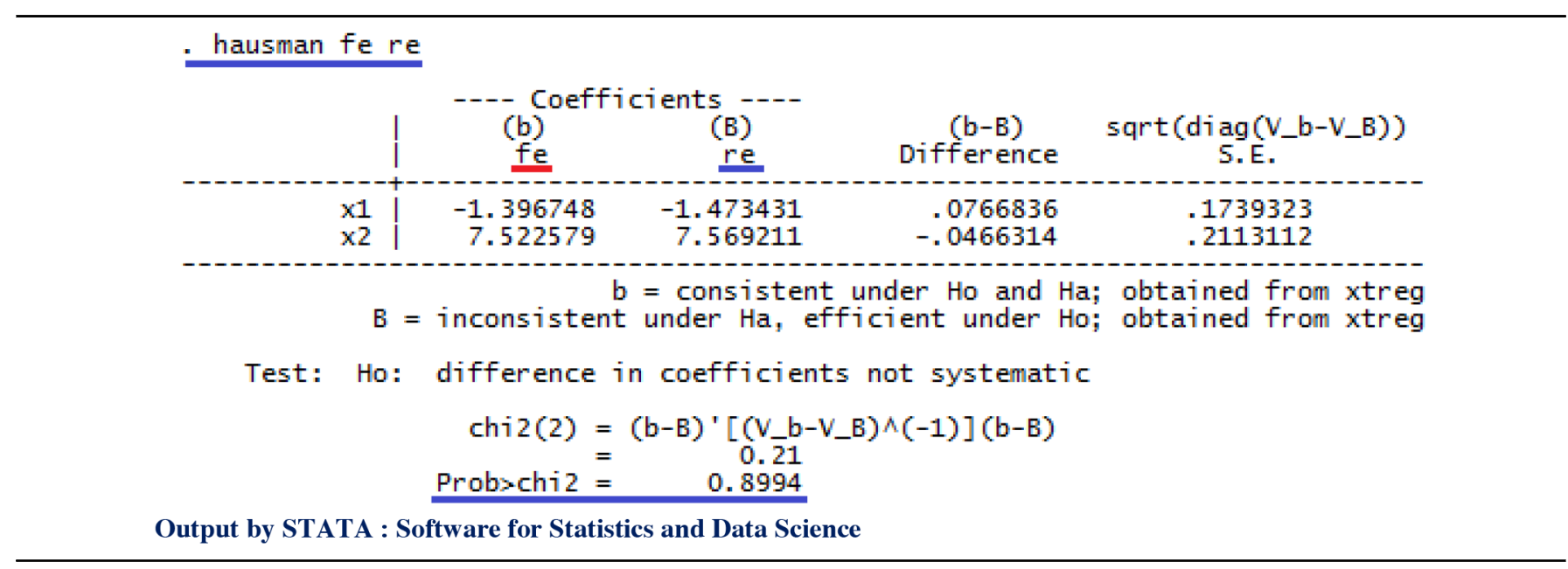

Table 4. The regression of variables on the portion allocated to equity investments.

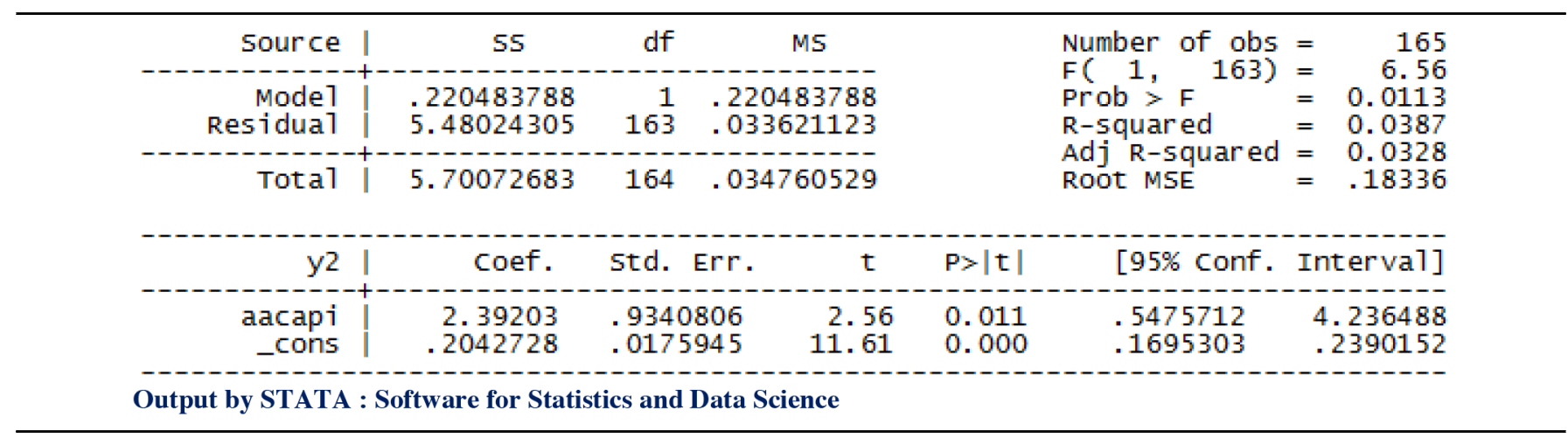

This is due to the prudential rules of insurance companies which considerably penalize the holding of shares and to the self-fulfilling dynamic generated by the excessive volatility of stock prices which discourages institutional investors who exit or hesitate to access at the stock market. Short-term investors take advantage of this high volatility to generate short-term capital gains, thereby accentuating the problem of market volatility.

The long-termism that characterizes investments on the stock market in the form of strategic investments by these national and foreign institutions constitutes an obstacle to the diversification of investment strategies on the Moroccan capital market. It is therefore necessary to develop management under mandate for institutional investors, whose profit-sharing formulas would make it possible to have a diversity of management styles that will surely impact the liquidity of the equity market [17].

The underperformance displayed by the financial market and more precisely the Casablanca Stock Exchange can only worry insurance companies, since their assets depreciate beyond a certain level, prudential provisioning rules can put companies in jeopardy, because it is the financial returns on their assets that allow them to optimize their profitability.

Insurers had significant unrealized capital gains, which were harvested during periods of upswing in the market, enabling them to cope with economic downturns. However, when the decline sets in over time, most insurance companies must set aside provisions for asset impairment to varying degrees.

The Gini index (or coefficient) is a synthetic indicator of inequalities. A drop in the Gini index observed between two dates indicates an overall decrease in inequalities. Conversely, an increase in the index reflects an overall increase in inequalities.

This index confirms the hypothesis of the existence of a form of mimicry between Moroccan investors. For example, in a period of crisis, we notice a deep drop in this index, which indicates that the inequalities in terms of behavior relating to allocations in shares are minimal. This year was marked by a dozen IPOs which improved the liquidity and return on stock market investments. The average shares of all investors 
increased significantly. The inequalities in investment decisions were almost similar for all fund managers. The GINI index has therefore fallen significantly.

After 2008, the effects of the crisis clearly influenced the behavior of some investors who made investment decisions too heterogeneous. This is illustrated by the accentuation of the GINI index whose value recorded the highest value over the period of analysis. The same observation has been observed in recent years.

\section{Recommendations relating to the supervision of asset management activity}

There are several factors of a macroeconomic nature - such as recurring deficits in public finances - which have had indirect and tangible consequences in the asset management market. However, most of the main obstacles to the development of this segment of the financial market are directly linked to the sector itself [18].

Examination of these obstacles makes it possible to propose the following recommendations:

- Put in place new simplified fund investment rules and strengthen the legal basis in order to better manage conflicts of interest.

- Provide a transparent budgetary [19] and accounting framework for investors and which converges towards international standards.

- Provide a legal and regulatory environment conducive to the development of new fund categories.

- Carry out official investigations to detect any form of collusion between asset management companies [20].

- Pursue the convergence towards international standards and provide a favorable environment for the development of Islamic funds to attract investors from the region, and in particular from Europe, North and West Africa and the countries of the Middle East). Foreign investors currently hold less than $1 \%$ of total assets under management and the development potential of this segment of the market is therefore strong. The creation of Sukuk, for example, should positively contribute to the development of Islamic funds.

\section{Conclusion}

This modeling of the allocations of Moroccan institutional investors allowed us to assess the dynamics of the Moroccan stock market and its causality with investment strategies, then to analyze their sensitivities to bearish stock cycles.

The results suggest that the share of equities in strategic allocations tends to be rather underweight. The equity market liquidity ratio is impacted by several macroeconomic and structural factors [21] related to the microstructure of the capital market. The interaction of these factors impacts both the arbitrage between investor assets and the liquidation of the Casablanca Stock Exchange.

Second, it has been found that institutional investors act simultaneously in the market but with sometimes divergent behaviors during turbulent times of the market when volatility is considered excessive. This observation is justified by the financial and structural constraints which differ according to the weight of the investor who will be able to invest in a longterm approach only if his reserves and their fruiting rules allow it.

Thus, the reform of the Moroccan financial market should take into consideration all the constraints that concern the stakeholders who operate there. Institutional investors play a very important role in the financial market and the development of its liquidity [22].

If this category of investors is not sufficiently integrated into the economic landscape from a regulatory and institutional perspective, it will not be able to determine its positioning as "long agents" who channel savings and finance the economy in strong proportions.

\section{References}

1. M. Sultonov, The impacts of international political and economic events on Japanese financial Markets, Int. J. Financial Stud. 8, 43 (2020)

2. T. Bahjat Sabri, The Investment in Fixed Assets Before and After the Global Financial Crisis (Empirical Study for Industry and Investment Sector in Palestine Stock Exchange), Int. J. Financ. Res. 12 (2021)

3. T. Singh, M. Gupta, The role of investor behavioral biases in investment decisions, J. Distrib. Sci. 13, 31-37 (2015)

4. M. Kacperczyk, The Review of Financial Studies, Volume 21, November 2008

5. Kosowski et al., Can Mutual Fund "Stars" Really Pick Stocks? New Evidence from a Bootstrap Analysis, J. Finance (2006)

6. R. Novy-Marx, J. Rauh, Public Pension Promises: How Big Are They and What Are They Worth? J. Finance 66, 1211-1249 (2011)

7. Xiong et al., 2010, The Equal Importance of Asset Allocation and Active Management, Financ. Anal. J (2010)

8. A. El Ghini, Y. Saidi, Return and volatility spillovers in the Moroccan stock market during the financial crisis, MPRA Paper No. 53439, 2014

9. B.H. Batalgi, Econometric analysis of panel data (John Wiley and Sons, New York, 2008), 4th edn.

10. J.M. Wooldridge, Econometric analysis of cross section and panel data (MIT Press, Cambridge, 2010), 2nd edn.

11. F. Bostanci, E. Kadioglu, G. Sayilgan, Determinants of dividend payout decisions: a dynamic panel data analysis of Turkish stock market, Int. J. Financial Stud. 6, 93 (2018)

12. I. Sahadudheen, An exponential GARCH approach to the effect of impulsiveness of Euro on Indian Stock Market, J. Asian Finance, Econ. Bus. 2, 17-22 (2015)

13. Md Aslam Mia, I. Tabet, Does microfinance institution has institutional properties to generate savings? J. Bus. Econ. Environ. Stud. 6, 11-14 (2016)

14. M.A. Siddiqui, N. Erum, Modeling effect of exchange rate volatility on growth of trade volume in Pakistan, J. Asian Finance Econ. Bus. 3, 33-39 (2016)

15. D.D. Nguyen, C. Minh, Search-based sentiment and stock market reactions: an empirical evidence in Vietnam, J. Asian Finance Econ. Bus. 5, 45-56 (2018) 
16. J.W. Lee, T. Brahmasrene, An exploration of dynamical relationships between macroeconomic variables and stock prices in Korea, J. Asian Finance Econ. Bus. 5, 7-17 (2018)

17. M.N. Alam, Md. Shabbir Alam, K. Chavali, Stock market response during COVID-19 lockdown period in India: an event study, J. Asian Finance Econ. Bus. 7, 131-137 (2020)

18. T. Dudycz, B. Brycz, Why the par value of share matters to investors, Int. J. Financial Stud. 9, 16 (2021)

19. W. Bessler Georgi Taushanov, D. Wolff, Optimal asset allocation strategies for international equity portfolios: a comparison of country versus industry optimization, J. Int. Financial Mark. Institut. Money 72 (2021)
20. W. Bessler, G. Taushanov, D. Wolff, Factor investing and asset allocation strategies: a comparison of factor versus sector optimization, J. Asset Manag. (2021)

21. Q. Yang, Z. Hong, R. Tian, T. Ye, L. Zhang, Asset allocation via machine learning and applications to equity portfolio management (2020)

22. N. El Hami, M. Bouchekourte, Optimising liquidity with modified particle swarm optimization application: case of Casablanca stock exchange, in 2016 4th IEEE International Colloquium on Information Science and Technology (CiSt) (2016), pp. $725-729$

Cite this article as: Mustapha Bouchekourte, Norelislam El Hami, Optimization of equity allocations of institutional investors: study of Moroccan case, Int. J. Simul. Multidisci. Des. Optim. 13, 12 (2022) 